\title{
PAUTAS PARA LA ATENCIÓN DE MUJERES VICTIMAS DE VIOLENCIA FAMILIAR
}

\section{RESUMEN}

Sabina Deza Villanueva*

En el presente articulo se formulan algunas sugerencias para los/as operadores/as de atención de la violencia familiar sobre como brindar un servicio de calidad a las mujeres afectadas por esta problemática. Asimismo, se brinda una serie de directrices para evitar la revictimización por los profesionales que abordan esta forma de violencia de género. En el texto se precisa una serie de consideraciones para facilitar la expresión de las necesidades y expectativas de ayuda de las mujeres frente a la violencia. Los temas desarrollados son los siguientes: Características y reacciones de las Mujeres afectadas por la violencia familiar, Razones por las cuales las mujeres no hablan sobre la violencia familiar que les afecta, y Pautas para una atención de calidad.

Palabras Claves: Mujer, violencia familiar, atención de calidad

\section{GUIDELINES FOR DEALING WITH FEMALE VICTIMES OF FAMILY VIOLENCE}

\begin{abstract}
This article makes some suggestions for operators care of family violence on how to provide quality service to women affected by this problem. Also it provides a set of guidelines to prevent revictimization by professionals that address this form of violence. The text requires a number of considerations to facilitate expression of the needs and expectations of help from women against violence. The topics covered are: Features and reactions of women affected by family violence. Reasons why women do not talk about family violence affects them, and Guidelines for quality care
\end{abstract}

Key words: Women, family violence, care quality

\footnotetext{
* Psicóloga. Master en Educación. Profesora Facultad de Psicología y Humanidades. UNIFE. Consultora Programa Nacional contra la Violencia Familiar y Sexual del MIMP y del Programa de Equidad de Género de la MML. Asesora Psicológica CMPFlora Tristán E-mail sdeza20@yahoo.com.

Recepción: 03-09-2012

Aceptación: 21-09-2012
} 


\section{CARACTERÍSTICAS Y REACCIONES DE LAS MUJERES AFECTADAS POR LA VIOLENCIA FAMILIAR}

Las mujeres que viven situaciones de violencia familiar y/o sexual son muy sensibles al trato que se les da. Es indispensable mostrar respeto, cortesía e interés por ellas y sus problemas. El profesional que las atiende debe ofrecer a las usuarias un ambiente que les inspire seguridad y confianza, considerando lo siguiente:

\section{Inicialmente}

- Sorpresa, asombro.

- Confusión

- Excusar el comportamiento del agresor, racionalizar, aceptar promesas de que no volverá a ocurrir.

- Mantener en secreto el maltrato.

\section{Después de varios episodios de Violencia}

La valoración de casos de mujeres maltratadas, ha permitido identificar las características que generalmente presentan las víctimas y que se manifiestan en:

a) Baja autoestima: Las mujeres maltratadas sufren la pérdida de su valía personal, del amor hacia sí mismas y del respeto que merecen, no se sienten aptas para manejarse en los diferentes ámbitos de su vida.

b) Aislamiento: Tienen la sensación de ser las únicas a las cuales les ocurre la violencia y además, ya sea por ellas mismas, por imposibilidad de comunicarse con los demás o por imposición de quien las agrede, han roto con sus redes sociales. Esto les hace tener una sensación constante de soledad.

c) Miedo al agresor: Este sentimiento se basa en una serie de amenazas o manipulaciones, además de las mismas experiencias de violencia vividas.

d) Inseguridad: Imposibilidad o restricción de posibilidades para tomar decisiones, derivada de la poca seguridad que le proporciona la convivencia con el agresor, y la transmisión de la idea de un mundo amenazante para ellas, ante el cual no les será fácil enfrentarse, ya que por efectos de la victimización están muy mermadas sus habilidades personales y sociales. 
e) Sentimientos ambivalentes de amor y odio hacia su pareja, puesto que él no es todo el tiempo violento y es posible que tenga cualidades que ella aprecia.

f) Depresión: La pérdida del sentido de la vida, se manifiesta como una forma de tristeza muy profunda por no haber podido mantener la relación, la armonía del hogar, la estabilidad de los hijos, por no haber cubierto las expectativas que se esperaban de ella o por haber roto la estructura familiar. Tienen una visión muy gris de su propia vida con pocas situaciones esperanzadoras.

g) Vergüenza: Tienden a guardar silencio sobre su situación o presentan dificultades para verbalizar su experiencia ya que se culpabilizan por lo que les ocurre.

h) Culpa: Tienden a asumir que lo que está pasando es responsabilidad sólo de ellas, y que como no están haciendo las cosas bien, merecen ser maltratadas.

i) Co-dependencia: Ante la cotidianidad de la violencia se genera una relación de dependencia mutua de forma tal que sus decisiones dependen de la aprobación del otro, para sentir, pensar y actuar.

\section{Además suelen sentirse:}

a) Propiciadoras de hechos violentos.

b) Causantes de la infelicidad de los hijos.

d) Incapaces de satisfacer a su pareja.

e) Carentes de habilidades cognitivas, conductuales y afectivas, necesarias en el manejo adecuado de la violencia emitida por el agresor.

f) La ira generada por la violencia recibida es canalizada en primera instancia hacia los hijos y hacia ellas mismas.

g) La cólera dirigida hacia ellas mismas puede observarse en las reacciones psicosomáticas que presentan, como enfermedades dermatológicas, cefaleas, insomnio, falta o exceso de apetito, alta o baja presión arterial, ulceras, gastritis, diarreas y otras enfermedades gastrointestinales.

h) Con pobre capacidad de poder cambiar su estilo de vida, más bien colocan el poder siemprefuera de ellas. 
RAZONES POR LAS CUALES LAS MUJERES NO HABLAN SOBRE LA VIOLENCIA FAMULIAR QUE LES AFECTA.

1. Tiene miedo a represalias si el agresor se entera de que su violencia ha sidorevelada:

a) No sabe cómo se va a manejar la información que proporcione, desconoce que lo que ella le dice al profesional es información confidencial.

b) Teme que una denuncia a la policía desencadene un estallido de violencia que ponga en peligro su vida y la de sus hijos.

c) El agresor ha amenazado con matarla a ella o a sus hijos si cuenta lo sucedido.

2. Siente vergüenza y culpa:

a) Cree que es la única que vive esta situación.

b) Piensa que ella provocó la violencia al haber fallado a su pareja de alguna manera (por ejemplo, al no limpiar bien la casa, al educar mal a los hijos, al vestir de forma inadecuada etcétera).

c) Pudo haber intentado dejarlo anteriormente, y al no haber sido capaz se siente avergonzada.

3. Cree que merece el maltrato:

a) Siente que no merece ser ayudada.

b) Piensa que es consecuencia de haber actuado mal.

c) Cree que es ella quien provoca las peores actitudes en su pareja.

4. Quiere proteger a su pareja:

a) El es su principal fuente de amor y afecto, cuando no la maltrata.

b) El es el único soporte de ella y sus hijos.

c) Ella espera que él cambie

5. Desconoce qué le está pasando:

a) Piensa que todas las parejas tienen peleas como las de ellos.

b) Cree que la violencia no se repetirá.

c) No es consciente de que sus síntomas físicos están relacionados con el estrés de vivir en una relación abusiva.

d) Considera que las lesiones sufridas no son lo suficientemente importantes como para mencionarlas.

e) Se siente presionada para soportar la situación. 
6. Cree que el operador de servicios no dispone de información o no se interesa lo suficiente sobre la violencia familiar como para hablarle de la situación:

a) Percibe que está muy ocupado $u$ ocupada como para perder tiempo hablando con ella de su problema.

b) Teme por la respuesta que pueda tener; cree que su problema no va a ser tomado en serio.

7. Piensa que no la pueden ayudar con su problema:

a) Desconoce que pueden brindarle información que ella necesita.

b) Recuerda situaciones anteriores en las cuales acudió en busca de ayuda, y no se le prestó atención.

\section{PAUTAS PARA UNA ATENCIÓN DE CALIDAD}

El objetivo de la atención debe ser brindar un servicio de calidad que satisfaga las expectativas y necesidades de las víctimas de violencia de género y que va a permitir darles bienestar. Aquí se considera, desde el trato adecuado que brinda el personal policial, de salud, o judicial a los/as usuarias/ os hasta la investigación que se realiza por la denuncia.

Se sugiere especial cuidado en los siguientes aspectos:

\section{a) CONTACTO VISUAL}

Toda buena comunicación requiere de un buen contacto visual. Es posible que las usuarias tiendan a mantener una actitud visual esquiva (mirar hacia abajo, hacia otro lado, hacia un punto fijo).Si ello sucede, el Profesional debe mantener su rostro hacia la usuaria tratando de promover un contacto visual agradable que demuestre interés en lo que esta manifestando.

\section{b) COMUNICAR CON NUESTRO CUERPO}

Establecer una distancia adecuada entre el profesional y la usuaria que pueda contribuir a una buena comunicación. Si nos inclinamos hacia atrás podemos estar trasmitiendo rechazo. En cambio, si inclinamos el cuerpo hacia nuestra interlocutora estamos demostrando interés. Si cruzamos los brazos e inclinamos la cabeza hacia el piso podemos estar trasmitiendo desinterés, o si nos mantenemos en una postura rígida e inexpresiva podemos aumentar la 
tensión. Es muy importante estar atentos a la actitud corporal de la usuaria y a las posturas que adoptamos durante las entrevistas.

\section{c) TONO DE VOZ}

Hablar rápida y atropelladamente podría expresar que existe mucha ansiedad en la usuaria; tonos de voz muy bajos y un hablar lento expresan desaliento o tristeza; hablar en tono muy alto puede indicar enojo, disgusto. Para lograr una buena comunicación hay que estar atento no sólo al significado de las palabras, sino también al tono en que se dicen las cosas. Por otro lado se debe evitar la monotonía en su voz. Si se considera que es necesario reforzar una idea, debe ponerse énfasis en su tono.

Durante las entrevistas debemos realizar preguntas adecuadas, ofrecer respuestas pertinentes y tratar de mantener el centro de la entrevista.

\section{d) PREGUNTAS}

Las preguntas abiertas permiten que la persona elija cómo contestar la pregunta; ofrecen más libertad para expresar sus sentimientos, ideas o su versión de los hechos

Algunos ejemplos son: ¿En qué ocasiones su esposo actúa con violencia? ¿Podría contarme algo de su esposo? ¿Podría narrarnos qué sucedió el domingo pasado? ¿Cómo la trataba cuando recién se conocieron? Este tipo de preguntas permiten que nuestro interlocutor ejerza cierto control sobre el rumbo de la conversación.

Las preguntas cerradas son aquellas que exigen una respuesta concreta. Se emplean cuando queremos verificar algún dato o información. Hay que evitar las preguntas cerradas de tono agresivo pues pueden generar una actitud defensiva en nuestra interlocutora.

\section{e) MANTENER EL CENTRO DELA ENTREVISTA}

Con el objetivo de evitar la dispersión o que no se llegue a tener los datos necesarios del problema son muy útiles las preguntas, comentarios, resúmenes o repetir lo que en algún momento se dijo durante la entrevista. 
Si nuestro interés es mantener el centro en lo que siente, piensa o hizo la persona con quien estamos conversando, podemos emplear como recurso preguntas que se dirijan directamente hacia la persona, por ejemplo: "Usted estaba diciendo que cuando su esposo toma licor, siente mucha rabia, me pregunto ¿cómo se siente ahora?" o "Estaba contando que cuando vio la libreta de notas de su hijo se enfureció y por eso golpeó al niño, ¿cree usted que golpeándolos mejorarán sus notas?".

En ocasiones es necesario profundizar lo que siente o piensa con respecto a las otras personas que están involucradas en el conflicto. "Usted ha hablado de sus hijos y su esposo, ¿quisiera decirme algo más de su familia?" (pregunta abierta). "Señora, ¿de qué conversa con su esposo?" (pregunta aparentemente abierta pero que permite iniciar una conversación acerca de la comunicación en la familia).

\section{f) ELEGIR ADECUADAMENTE LOS TIEMPOS VERBALES}

Es mas fácil hablar del pasado y del futuro que del presente.

Al hablar en pasado se puede propiciar el análisis de los acontecimientos; la actitud y factores que influyeron, la conducta y los sentimientos que tuvieron las personas en que se producían los hechos de violencia.

El tiempo presente tiene que ver con el momento mismo de la entrevista y permite que se dialogue acerca de lo que en esos instantes sienten, piensan y desean.

Al emplear el tiempo futuro podemos motivar el diálogo acerca de las alternativas de solución al conflicto y las decisiones que van a tomar.

\section{g) PRACTICAR UNA ESCUCHA ACTIVA}

Es importante que la usuaria perciba que se le escucha con atención. Algunas señales de escucha activa pueden ser inclinar el cuerpo o la cabeza hacia el interlocutor o decir palabras o interjecciones que demuestren que estamos atentos, por ejemplo: $m m m m m$, ajá, entiendo, siga, entre otras.

Resumir de manera fiel lo que nos ha manifestado, ayuda a que la interlocutora perciba que la estamos escuchando con atención. Además, el 
repetir las ideas, hechos o sentimientos que expresó durante la entrevista le ofrece la oportunidad de analizar nuevamente la situación.

Esto exige mucha práctica ya que no es fácil resumir con exactitud los hechos o sentimientos que nos han expresado.

\section{STTUACIONES CRITICAS DURANTE LA ENTREVISTA}

a. La persona se siente incómoda por el sexo o edad del profesional.

Puede ocurrir que nos plantee su incomodidad directamente o que no la señale. Si percibimos esta situación el Profesional debe manifestar directamente que comprende su incomodidad. "Señora, tal vez Usted preferiría hablar con una mujer" o "señor, ¿quizá usted esperaba ser atendido por alguien con más edad?" Una vez planteada la cuestión es importante tratar de minimizar la dificultad y dar seguridad. Por ejemplo, podemos decir: "Al principio algunas personas se sienten más cómodas con alguien de su mismo sexo (o del sexo opuesto) o más edad, pero mi experiencia me dice que a medida que nos vamos conociendo esto pierde importancia. ¿Por qué no tratamos de ver si logramos encontrar soluciones?"

b. El profesional no tiene tiempo suficiente para atenderla.

Es conveniente que las usuarias estén informadas del tiempo de que dispone el profesional para atenderlas. Si no cuenta con mucho tiempo explíqueles el motivo y discúlpese.

c. El profesional y la usuaria se conocen.

Es frecuente, sobre todo en localidades pequeñas, que los profesionales y las usuarias se conozcan. Si se trata de una relación circunstancial, desde el inicio debe quedar muy claro para ambos que se guardará absoluta reserva de lo que se converse.

Si ambos se conocen estrechamente, es preferible explicar que no es conveniente que el caso sea atendido por el profesional. Hay que diferenciar la labor del profesional de la del amigo, conocido o familiar que puede ofrecer apoyoy orientación.

d. El usuario habla sin interrupción e inapropiadamente.

Durante las entrevistas o en ocasiones las personas hablan 
incesantemente y se refieren a hechos triviales o los repiten. Ello puede ser producto de la ansiedad o que están evitando hablar del tema principal Luego de unos minutos podemos interrumpirlos planteándoles centrar la conversación en otro punto.

e. La entrevistada entra en crisis.

Durante la conversación pueden producirse crisis de llanto. En estas situaciones hay que tratar de calmar a la usuaria, ofrecerle un vaso con agua, pañuelos desechables, etc.

Podemos manifestar que sabemos que necesita llorar para desahogarse y que eso no nos molesta. Es oportuno preguntarle si desea suspender por unos momentos la conversación.

Se puede revictimizar a las mujeres al:

- Violar la confidencialidad.

- Restar importancia al maltrato y minimizarlo.

- Culpar a la víctima.

- Concentrarse en ella como si fuera el problema.

- No respetar la autonomía de la mujer.

- Ignorar la necesidad de la seguridad de la mujer.

- Convertir en algo normal el hecho de ser una víctima.

O, favorecer su recuperación al:

- Respetar la confidencialidad.

- Creer y validar las experiencias de la mujer.

- Reconocer la injusticia.

- Respetar la autonomía de la mujer.

- Ayudarle a elaborar un plan para su seguridad futura.

- Promover el acceso a los servicios comunitarios. 


\section{REFERENCIAS}

Baca,M.E., y Col. (1998) Los caminos de las mujeres que rompen el silencio. Lima: OPS.

Ceres. (1998) Mujeres contra la violencia doméstica. Comisión para los asuntos de la mujer. Puerto Rico.

Corsi, J. (1995) Violencia Familiar. Buenos Aires: Paidos.

Deza, S. (1998) La violencia psicológica y sus efectos en la salud mental de las mujeres. En Avances en Psicología y Mujer. Lima: UNIFÉ.

Dpto. de la Familia. Policía de la Capital. (1997). En Comunidad podemos. Campaña de Prevención del Abuso Físico y Sexual. Asunción.

Ferreira, G. (1995) Hombres violentos. Mujeres maltratadas. Buenos Aires: Sudamericana.

INCAFAM - PROMUDEH. (1998) Pautas de Prevención y atención de la violencia familiar para personal policial. Lima.

RADDA BARNEN (1996) Maltrato. Violencia Familiar. Cuadernos de Trabajo. DEMUNAS. Lima.

RSMLA (1996) Por el derecho a vivir sin violencia. Santiago de Chile.

Venguer, T. y Col. (1998) Violencia Doméstica. Un marco conceptual para la capacitación del personal de salud. México: IMIFAP.

Villavicencio, P. y Col. (1993) Mitos y realidades sobre el maltrato contra la mujer. En: Revista de Psicología. / Octubre 93. UNIFÉ. Lima. 